\title{
ENTRE O VERBAL E O VISUAL: O HAIKAI E A FOTOGRAFIA NA POÉTICA DE PAULO LEMINSKI
}

Ana Maria Abrahão dos Santos Oliveira ${ }^{1}$

Resumo: Este artigo pretende discutir a poética de Paulo Leminski, em especial, o haikai, destacando sua relação com a fotografia. Primeiramente apresenta um breve resumo sobre a questão do olhar desde a Antigüidade Clássica até a Modernidade. Será discutida também a mesma questão, dando ênfase à poesia moderna, em especial, os haikais, relacionando-a com o olhar fotográfico.

Palavras-chave: Poesia moderna, Haikai, Fotografia, Paulo Leminski.

Abstract. This article intends to discuss Paulo Leminsky's poetry, especially the haikus, highlighting their relation to photography. It begins with a brief summary concerning the question of the look, from classical antiquity to modern times. The same question will be discussed with an emphasis on modern poetry, particularly haikus, in relation to the photographic look.

Key words: Modern poetry, Haikai, Photograph, Paulo Leminski.

\section{O OLHAR E AS IMAGENS NA MODERNIDADE}

Estamos impregnados pelo campo semântico do olhar. Quando falamos em "amor à primeira vista", ou até mesmo, "é claro", "logo se vê"; não nos esquecendo da expressão cunhada por São Tomé, na Bíblia: "ver para crer". Partindo do princípio de que tudo é visível, temos o provérbio: "o pior cego é aquele que não quer ver".

O olhar pode representar perigo: Orfeu perde Eurídice; Édipo cega-se para conseguir enxergar, porque com os olhos sãos não logra a visão; Perseu induz Medusa a olhar para si mesma e assim, provar de seu próprio veneno; Narciso perdese de si mesmo ao contemplar-se no espelho das águas; a mulher de Ló olha para trás e, por isso, transforma-se em estátua de sal; os índios receavam ver sua imagem no espelho, porquanto o recusavam, crendo que a imagem refletida era a própria alma e que a perderiam, se por acaso, a vissem.

Pode ser fonte de poder, já que o olhar tem força para despir, devorar, matar. Assim, nos remetemos a Sartre ("O inferno são os outros"), pois o olhar transforma-nos em coisa, abstraindo-nos da condição de sujeito, estimulando a insatisfação e o temor.

O "olhar de medusa" governa a nossa sociedade: fascina e petrifica. Por ter valor duplo, seriam dois os aspectos do gozo - o prazer e o desprazer - o que faz

1 Mestre em Literatura Brasileira e Teorias da Literatura pela Universidade Federal Fluminense - UFF. Membro do Grupo de Estudos Nação-Narração - UFF/CNPq. Endereço eletrônico:abrahao-ana@ig.com.br. 
com que o olhar seja causa de alegria e, ao mesmo tempo, objeto de angústia. Janela e também espelho, os pintores dizem que, no olhar, percebem-se olhados pelas coisas que ver é uma experiência mágica.

Sendo escópica, é uma sociedade do espetáculo em que a produção do olhar é privilegiada: o desejo de fama, de ser celebridade, enfim, de ser visto por alguém. Impera também o controle policialesco em que todos devem ser vigiados todo o tempo. Neste caso, temos o exemplo, no Brasil, que, tal como nos Estados Unidos, veicula através de uma importante emissora de televisão, o programa Big Brother, que aparece também em outras emissoras de menor audiência com nomes diferentes, cujos índices de audiência são altíssimos, pois para os espectadores, o importante é vigiar o tempo todo os participantes que se encontram numa casa onde têm de permanecer por um período determinado sem terem contato com o exterior, para deleite de milhões de pessoas que os vêem, muitas vezes em situações aviltantes e constrangedoras, provavelmente simulacros muito bem elaborados pelos diretores responsáveis pelo programa.

"Ver é ter à distância" (MERLEAU-PONTY, 1969, p. 44), porque o olhar apodera-se dos demais sentidos. Ultrapassa-os porque os realiza naquilo que lhes é vedado pelos limites do corpo, a saída de si, sem sofrer alteração material.

Na Grécia Antiga já se valorizavam os olhos por considerá-los um portal de entrada, por estarem na fronteira entre a materialidade e a espiritualidade. Sendo a visão o sentido mais importante para os gregos, era para eles a fonte de sabedoria; o olho - janela e espelho - órgão responsável por receber e espalhar a luz > lumina $>$ fogo $>$ divinização $>$ Deus. Na visão platônica, Deus é theorein, olhar eterno e o homem, receptáculo de sua luz (theoreticon), aquele que contempla toda a obra da luz.

Leonardo Da Vinci, ao discorrer sobre a importância do olhar, descreve o olho como "janela do corpo humano", de onde se pode especular a beleza do mundo. Um universo reduzido que capta as imagens do universo

$\mathrm{Na}$ sociedade moderna, toda a realidade afirma-se em imagens e as imagens todas se transformam em realidade. A realidade que a televisão transmite produz suas próprias referências e é difícil diferenciá-las da ficção. Existe um novo paradigma visual que muda profundamente a percepção e o reconhecimento da realidade.

As imagens são criadas por nós, muito além das fronteiras de nossa experiência. O valor da "verdade" da imagem diminui enquanto o valor da opinião aumenta. A divulgação mundial de notícias é um exemplo. Todos acompanham diariamente mesmo sabendo que as notícias podem ser, até certo ponto, fictícias. Impera o desejo de ver tudo o que os outros vêem para que fiquemos inteirados sobre o estado geral do imaginário global. 
Já no imaginário subjetivo, supõe-se a nossa fascinação pelas imagens exteriores, como se aquelas fossem uma extensão destas.

A identidade do sujeito regula-se num contínuo desvendar de imagens reflexivas. Assim, interpretamos a nós mesmos, dentro da realidade exterior. O real é a mais inacessível realidade que a linguagem tenta domesticar. Tem uma relação íntima com o desejo. O sujeito que olha tem uma relação de desejo.

Há uma dialética entre o imaginário individual e o imaginário coletivo, em que a visibilidade e a manifestação visual convertem-se em fator relevante para a nossa identidade pessoal. Vemos o mundo de um modo e ele só é o que é porque o vemos desta maneira. Se somos o que somos é porque assim que nos vemos no mundo real e tentamos fazer com que os outros nos vejam desse mesmo jeito. "Vejo logo sou" ou "eu me vejo logo sou". Esta paródia cartesiana faz com que nos iludamos, a ponto de pensarmos que só alcançaremos o que almejamos, se formos vistos por outrem, isto é, se conseguirmos aparecer; não tanto para afirmar a própria identidade quanto para procurar um vínculo com a coletividade. É o olhar do outro que me vê. O diálogo entre o imaginário do sujeito coletivo faz referência a uma separação mais relevante no próprio olhar humano.

Já na Antigüidade havia uma inquietação com relação à representatividade da profundidade visual. Na Idade Média, a profundidade transforma-se em superfície. Pessoas, objetos e passagens são expostos em semelhante nível de visão e de leitura.

Posteriormente, na Renascença, lugar do vago e do ambíguo, dá-se a homogeneização do espaço da representação, calcada na preocupação de representar as coisas não como eram realmente, através de nossa captação "enganadora" pelos sentidos, mas também como surgiam para o olhar do sujeito "cognitivo" ideal, que tem conhecimento de sua autonomia em relação ao mundo exterior.

No Barroco, cuja "sedução específica consiste na primazia que vem ocupar a estética - as aparências e o jogo" (SCHÖLLAMMER, 2002, p. 82), importam os detalhes, o fragmento e as imagens alegóricas que aludem à "alteridade" (allos = "outro"). A imagem tem um poder sensual, erótico.

É no Romantismo que se manifesta a busca da linguagem do irrepresentável: a transcendência, o divino, o sublime. Paralelamente a isso, dá-se a descoberta do "estranho inquietante" em que se encontra a funesta alteridade naquilo que parece ser mais familiar. Assim, temos o exemplo do conto $O$ homem de areia, de E. T. Hoffmann. O "monstro" está dentro de cada um de nós.

$\mathrm{Na}$ obra de Charles Baudelaire, o último romântico e o primeiro moderno, há um embate entre o desejo de todo ver e a curiosidade de ver outra coisa ou a mesma coisa de outro modo. Para o poeta francês, no coração da modernidade, oculta-se como condição e limite da "monstruosa alteridade", do estranho, do feminino e da morte. No feminino, a fenda, a "falha", a ausência do falo. A mulher 
seria o "outro" do homem; a morte, o "outro" dentro de nós mesmos, o "outro" que nós queremos negar. Baudelaire foi um poeta paradoxal: muito atento às regras formais em seus poemas mas, por outro lado, introdutor de temas até então considerados antipoéticos, escatológicos. Levou o prosaico para a poesia, o lixo, o grotesco, a cidade, de forma elegante, valendo-se de um vocabulário inusual. Concebeu a poesia como maldição e heró́smo. Rimbaud, discípulo do poeta de As flores do mal, conceberá a arte poética como rebelião e vidência. Na poesia de Rimbaud, a associação livre das imagens evocadas cria uma comunicação extra-racional, em que zonas obscuras e zonas luminosas se alternam.

Com Baudelaire, exprime-se a voz do homem moderno como um ser caído e com a alma dividida; o que faz de Baudelaire um poeta moderno não é tanto a ruptura com o mundo da ordem divina, mas a consciência dessa ruptura. Diz Baudelaire: "Tanto no espiritual como no natural, é significativo, recíproco, correspondente [...] tudo é hieróglifo [...] e o poeta é apenas o tradutor, aquele que decifra [...]" (apud PAZ, 1980, p. 89).

O embate da modernidade ocorre entre o mundo estável da tradição e a percepção do olhar em movimento, devido à rápida mudança das impressões visuais.

Transpondo-nos para a moderna Literatura Brasileira, já no século XX, fazendo um recorte, com enfoque na geração de 1970, as questões referentes ao olhar e à poesia, em especial, estão muito bem ilustradas na obra do poeta curitibano Paulo Leminski (1944-1989).

A marca poética da década de 1970 veio, desde o seu começo, tocada pelo impacto de uma geração (a geração "marginal"), que redigia e atuava de modo diverso de seus antecessores da década anterior, sendo esses últimos concretistas ou neomodernistas do engajamento. Situam-se de forma oscilante, diante de dois cânones bem diferentes: o legado modernista e o modelo cabralino-concretista.No primeiro caso, escrevia-se sob a inspiração da "poesia-pau-brasil", de Oswald de Andrade; no segundo, a poesia era construída, conjugando-se a desaparição elocutória do eu e a postura de uma estética de rigor. O rótulo "marginal" foi atribuído a maior parte dos jovens poetas que estreavam nos idos dos anos 70, (Paulo Leminski, Ana Cristina, César, Chacal e outros), cuja produção era realizada de forma independente, em outros locais que não as editoras, o que remetia, assim, à "marginalidade", como sua característica mais marcante.

\section{A Poética de Paulo Leminski e os Haikais}

Formadora de poderosas imagens culturais que moldaram homens, terras, instituiçoes e vaLores, a Literatura Brasileira mantém uma rica interação com imagens visuais, geradas pela pintura, fotografia, o que também revela, em contrapartida, um traço de nossa bistória cultural: o fascinio pela imagem (FIGUEIREDO, 2006, p. 1). 
Paulo Leminski, poeta da chamada "geração marginal", foi contemporâneo dos Beatles, Roling Stones, Bob Dylan, Glauber Rocha, Torquato Neto, Caetano Veloso, Gilberto Gil, Chico Buarque, Zé Celso Martinez e "tantos outros poetas das palavras e das imagens" (VERÇOSA, 1996, p. 468) grifo nosso. O foco de interesse do poeta possuía uma multiplicidade que fazia alusão a várias épocas e culturas:

[...] da poesia clássica chinesa ao blues afroamericano, da patafísica de Jarry ao vigor samurai de Yukio Mishin, dos clássicos gregos ao rock in roll, do baikai japonês ao tropicalismo, de Cruz e Sousa a Leon Trostky, de James Joyce a John Fante, de Samuel Beckett a Cartola, de poemas do Egito Antigo ao videotexto, do supraerudito ao supremo popular, do universo cósmico de uma biblioteca aos movimentos mundanos (ASSUNÇÃO, 1999, p. 22).

O poeta soube construir pontes entre os mais diversos tecidos culturais. De repertório vasto, era um artista denso e extremamente criativo. Autodenominou-se “poeta da geração 68”, quando publicou seus poemas na revista Pólo Inventiva, em 1978. Pertencia a uma geração marcada pela rebeldia contra os cânones literários, pela poesia experimental, pelo inconformismo, pelas utopias.

Dentre alguns aspectos do contexto histórico e cultural que foram focalizados por Leminski, poderíamos destacar: contestação e os powers (black red, gay, women' lib), a pílula, o aborto, a guerra do Vietnã, psicodelismo zen, sociedade alternativa, o rock, o homem na lua, a contracultura. Não obstante, Leminski era um erudito. Conhecia poesia profundamente, porém, não era um intelectual "bem comportado". Era extremamente inquieto. "Um bandido que sabia latim", como se autodenominava, ou até mesmo com uma outra definição de si mesmo:

O pauloleminski é um cachorro louco

que deve ser morto

a pau a pedra

a fogo a pique

senão é bem capaz

o filhodaputa

de fazer chover

em nosso piquenique (MARINS; GÓES et al., 2002, p. 130).

Toda essa impetuosidade marcou intimamente sua poesia. Sua rápida e telegráfica disposição das frases, no escrever e no falar, faz lembrar um samurai experiente, dando um golpe de espada, como assinala brilhantemente Leila PerroneMoisés:

Samurai e malandro, Leminski ganha a aposta do poema, ora por um golpe de lâmina, ora por um jogo de cintura. Tão rápido que nos pega de surpresa; quando menos se espera, o poema já está ali. E então o golpe ou a ginga que o pro- 
duziu parece tão simples que é quase um desaforo (PERRONE-MOISÉS, 2000, p. 235).

acordei bemol

tudo estava sustenido

sol fazia

só não fazia sentido (LEMINSKI apud PERRONE-MOISÉS, 2000, p. 235).

Leminski era "samurai" e "malandro". Samurai, em seus "caprichos" e malandro, em seus "relaxos":

Samurai:

nuvens brancas

passam

em brancas nuvens

Malandro:

não discuto

com o destino

o que pintar

eu assino

Samurai-malandro:

a palmeira estremece

palmas pra ela

que ela merece (LEMINSKI apud PERRONE-MOISÉS, 2000, p. 235-236).

Retornando aos anos 60, teremos uma visão geral da curta, mas excepcional trajetória de Paulo Leminski. No contexto poético da Semana Nacional da Poesia de Vanguarda (Belo Horizonte, 1963), surgem críticos, intelectuais, tradutores e poetas - Augusto e Haroldo de Campos, Benedito Nunes, Décio Pignatari, Luís Costa Lima e outros e também o jovem poeta Paulo Leminski. Ele se envolve diretamente com a "ponta de lança" da vanguarda brasileira, como que antecipando a sua dicção singular.

Leminski publicou cinco poemas na revista Invenção $\mathrm{n}^{\circ} 4$ e mais quatro poemas na Invenção n 5, em 1964 e 1965, respectivamente. Dedicou-se ao estudo de idiomas (inclusive orientais) como ponte para suas experiências poéticas. Dentre os poemas publicados na primeira revista, está este, em que o poeta, gradativamente corta a frase, concentrando a semântica do texto a fim de questionar a forma do poema:

por questão de subsistência

por questão de subserviência

por questão de subseqüência

por questão de silêncio 
por questão de ânsia

por questão de cio

por questão de se

os que estão

em questão (LEMINSKI apud BOVINCINO, 1992, p. 156).

$\mathrm{Na}$ Invenção $\mathrm{n}^{\circ} 5$, o poeta publicaria poemas com maior abertura semântica, revelando a influência da poética oriental (o baikai, basicamente), que são um prenúncio do que viria a escrever mais tarde:

hai-cai: haifi

chove

na única

q'houve

cavalo com guizos

sigo com os olhos

e me cavalizo

de espanto

espontânea oh

espantânea (LEMINSKI apud BOVINCINO, 1992, p. 157).

A revista, onde aconteceu a estréia poética de Paulo Leminski, foi considerada por ele como uma publicação pioneira de todo o movimento editorial (a "imprensa nanica”), que ganhou impulso a partir dos anos 70, no Brasil.

Depois do "filtro" inicial do concretismo, partiria rumo a uma criação de uma dicção própria que se realizaria por uma saída pessoal para questões teóricas, exaltadas pelo movimento e da prática que desenvolveu em diversos textos, de cunho experimental. A opção pela "várzea" relaciona-se também com o encontro da poesia concreta e a tropicália, definido pelo próprio Leminski como "pororoca" (encontro de duas águas, duas margens que gerariam uma terceira linguagem linguagem construtivo-tropical).

Tendo conhecimento das rebeliões comportamentais e da negação do intelectual clássico, Leminski achava que fazia necessária a explosão de uma outra rebelião, a da linguagem. Questionou o racionalismo aristotélico-cartesiano. Fazia experiência com o próprio texto. Para não refletir a realidade, transformava a escrita numa realidade em si. Os poemas tornavam-se experiências que englobavam, cada vez mais, uma totalidade corporal:

quem nunca viu

que a flor, a faca e a fera

tanto fez como tanto faz

e a forte flor que a faca faz 
na fraca carne,

um pouco menos, um pouco mais

quem nunca viu

a ternura que vai

no fio da lâmina samurai

esse, nunca vai ser capaz (LEMINSKI apud BOVINCINO, 1992, p. 156).

Com a publicação de Catatau (1975), prosa experimental, "o não-livro" no mesmo sentido em que Haroldo de campos definiu Serafim Ponte Grande, de Oswald de Andrade, Leminski já estava anunciando sua estratégia. O protagonista do livro é Descartes, que se assombra com a paisagem tropical do Brasil, onde se vê atacado por mosquitos, jibóias, antas e preguiças. O filósofo francês, com seu pensamento lógico, é incapaz de desvendar o segredo da paisagem do Mundo Novo e espera alguém que lhe traga explicações.

Em 1976, publica Quarenta clics em Curitiba, poemas de Leminski com fotos de Jack Pires, imagens e palavras aproximados como ideogramas japoneses. Dessa aproximação, resultam aspectos cotidianos de Curitiba como cidade popular, habitada por pipoqueiros, menores abandonados, mendigos, biscateiros. O tempo, em todas as suas dimensões, reflete-se nos poemas e nos fatos e há também uma evocação de um ludismo criativo:

Quem me dera

Um mapa de tesouro

Que me leve a um velho baú

Cheios de mapas de tesouro (LEMINSKI apud MARQUES, 2001, p. 34).

Depois de publicar ensaios, traduções e o romance Agora é que são elas (1984), o poeta publica, em 1987, Distraídos Venceremos (trocadilho zen com o bordão "Unidos venceremos").

Em Caprichos e relaxos, 1983, reúne quase vinte anos de poesia. Inclui os livros Não fosse isso e era menos/ não fosse tanto e era quase, Polonaises e mais cinco sessões: a de abertura - homônima do livro - Ideolágrimas, Sol-te, Contos semióticos e Invenções. Este último é um bom exemplo da poética multifacetada de Leminski, onde há poemas semelhantes a frases de pára-choque de caminhão, grafites, baikais, versos epigramáticos, poemas concretos e textos semióticos.

Lançado postumamente, em 1994, apesar de ter sido concluído em 1988, Winterverno é um álbum de haiga, um diálogo entre o verbal e o visual. Versos de Leminski e desenhos de João Virmond estão escritos e rabiscados em guardanapos, embalagens, folhas de caderno.

Publicados também postumamente, os livros La vie em close (trocadilho autoreferente com a famosa canção interpretada por Edith Piaf, La vie em rose), 1991, com poemas selecionados em 1988 e O ex-estranho, 1996, mantêm características de 
livros anteriores, como o jogo de palavras explorando frases feitas, invenções léxicas, deformações ortográficas, trocadilho, montagem.

É importante destacar a paixão de Leminski pela cultura japonesa, pelo budismo zen, pela poesia de Matsuó Bashô (1664-1694), guerreiro defensor da nobreza feudal, samurai e posteriormente instrutor de haikai e monge budista.

A obra poética de Leminski é a de um guerreiro-poeta ou poeta-guerreiro, que maneja suas armas (sintáticas, semânticas e lexicais) com o intuito de dizer o máximo com o mínimo, nesta estrutura concentrada denominada haikai, a fim de ver

um pouco de mao

em todo o poema que ensina

quanto menor

mais do tamanho da China (LEMINSKI apud MARQUES, 2001, p. 32).

Reginald Blyth, um dos maiores estudiosos e tradutores de haikai, assevera que "se dizemos que o baikai é uma forma de zen-budismo, não quer dizer que afirmemos que o hakai pertence ao zen, mas sim que o zen pertence ao baikai" (apud MARQUES, 2001, p. 34).

O zen surgiu no século VI, no Japão, mas apenas a partir do período Muromachi (1533-1600) ganhará força na cultura japonesa. "Em Bashô, o haikai. No haikai, o żen. Dessa equação, Leminski se apropriou antropofagicamente, para enformar sua poesia." (MARQUES, 2001, p. 34, grifo nosso).

Ernest Fenollosa (1853-1908), um norte-americano que viveu muitos anos no Japão, tornou-se grande conhecedor da arte nipônica, é autor de um ensaio denominado Os caracteres da escrita chinesa como instrumento para a poesia que só foi editado em 1919, por Ezra Pound. Este trabalho de Fenollosa forneceu a Pound uma idéia de grande importância para o desenvolvimento de sua poética: a de que existiria, na poesia chinesa e na japonesa, um princípio extremamente eficaz e diferente da ordenação lógica ocidental. Nesse processo de composição, duas coisas que se somam, não produzem uma terceira, mas sugerem uma relação fundamental entre elas. É o princípio da montagem que presidiria, tanto a criação dos ideogramas, quanto as obras geradas numa civilização ideogramática (Cf. FRANCHETTI, 1990, p. 30).

O haik ai despertou a atenção de Ezra Pound: a colocação, lado a lado, estruturas verbais desprovidas de nexos sintáticos explícitos entre si, de modo que o leitor tenha de descobrir a relação entre elas. "Dessa aproximação poundiana com o ideograma, difundida aqui pela poesia concreta vai resultar, nos anos 70, a prática de Paulo Leminski que contribuiu como poucos para tornar o haikai popular" (FRANCHETTI, 1990, p. 30). 
Foi com Leminski que o haikai encontrou, fora da comunidade japonesa, a melhor realização no Brasil, e a mais conhecida. Seus haikais não seguem a métrica da poesia japonesa, como já vimos, mas não há a menor dúvida de que na sua poesia encontram-se presentes em alto grau algumas qualidades mais notáveis da poesia de haikai.

Para Otávio Paz, do ponto de vista formal, o haikai divide-se em duas partes:

Uma de condição geral e da ubiquação temporal ou espacial do poema (outono ou primavera, árvore ou rochedo) e outra relampagueante, que deve conter um elemento ativo. Esta, inesperada, a outra, descritiva e quase enunciativa. [...] sua poesia é uma verdadeiro calmante, embora a sua seja uma calma que não se parece nem com o letargo da droha nem com a modorra da digestão. Calma alerta que nos torna leves (apud MARQUES, 2001, p. 33).

Leminski apelava para a experiência irracional como origem do conhecimento para o haikai. Simultaneamente, mantinha com agudeza intelectual uma relação marcada pelo lúdico, num registro entre inocência e o deslumbramento da adaptação do baikai ao português, pois,

para ele confluíram tanto o enfoque da técnica do ideograma quanto o apelo vivencial, de vê-lo como caminho da vida, uma forma de trazer a poesia para dentro do cotidiano, identificando-o à exteriorização elegante e bem-humorada da experiência sensória mais elementar (FRANCHETTI, 1990, p. 40).

Muitos de seus poemas possuem um inconfundível "sabor de haikaı" e quanto à forma, uma grande liberdade, que ora permite o uso da rima e da assonância, ora utiliza o verso branco e sem medida, ora monta o poema visualmente, tirando partido do espaço e da forma física das palavras.

duas folhas na sandália

o outono

também quer andar (LEMINSKI apud MARINS; GÓES et al., 2002, p. 71).

a chuva é fraca

cresçam com força

línguas-de-vaca (LEMINSKI apud MARINS; GÓES et al., 2002, p. 72).

Para Leminski,

[...] o mundo que o baikai procura captar é um mundo objetivo, o mundo exterior. Um mundo de coisas onde o eu está sempre ausente, sujeito oculto, elidido. Mas não é um mundo morto, uma mera descrição. Por trás das objetividades do baikai, sempre pulsa (sem se anunciar) um $e n$ maior, aquele $e n$ que deixa as coisas ser, não as sufoca com seus medos e desejos, um $e n$ que quase confundo com elas. A este estado, os poetas japoneses chamam mi-ga, em japonês, não-en é o es- 
tado perfeito para fazer haikai. Os mestres japoneses gostavam de dizer que o bom haikai ninguém faz. Ele se faz sozinho, a hora que quiser, tudo o que o poeta pode fazer é suspender os egoísmos da subjetividade para permitir que a realidade se transforme em significado (LEMINSKI, 1986, p. 98).

O haikai procura captar aquilo que se confunde com o zen, o satori, uma iluminação, uma epifania projetada na página em branco.

Traça uma linha divisória que separa o instante privilegiado da corrente temporal: nesse aqui e nesse agora principia algo: um amor, um ato heróico, uma visão de divindade [...] Esse instante é ungido com uma luz especial: foi consagrado pela poesia, no melhor sentido da palavra consagração (MARQUES, 2001, p. 41).

"Ungido com uma luz especial", instante "consagrado pela poesia". Essas expressões ratificam em Leminski a existência de uma visão ligada à filosofia zen, "que valoriza o cotidiano e a instantaneidade, a materialidade e a imediatidade da experiência, contra a pobreza do pensamento conceptual e a tirania do mundo das palavras" (LEMINSKI, 1986, p. 98).

Leminski vai comparar o haikai à fotografia ${ }^{2}$. O poeta destaca duas características comuns à fotografia e ao poema japonês. Uma delas seria a irrepetibilidade, a outra, a intraduzibilidade.

O verdadeiro haikeai é aquele que desponta de súbito, íntegro, sólido objeto do mundo, num momento decisivo que não depende da vontade, do arbítrio do poeta. Como o ato de bater uma foto. A outra característica é a intraduzibilidade porque o que é irrepetível não pode ser traduzido, vertido, passado para outro sistema de signos. Fotos e haikais são coisas, coisas não têm tradução (LEMINSKI, 1986, p. 98, grifo nosso).

Walter Benjamin, ao discorrer sobre a importância da fotografia, enquanto imagem reveladora do inconsciente ótico, ressalta:

Apesar de toda a perícia do fotógrafo e de tudo o que existe de planejado em seu comportamento, o observador sente a necessidade irresistível de procurar nessa imagem a pequena centelha do acaso, do aqui e agora, [...]. A natureza que fala à câmara não é a mesma que fala ao olhar; é outra, especialmente porque substitui a um espaço trabalhado conscientemente pelo homem, um espaço que ele percorre inconscientemente (BENJAMIN, 1993, p. 94).

2 As primeiras câmeras fotográficas surgiram na França e na Inglaterra no começo da década de 1840 e somente inventores e aficcionados poderiam operá-las. Apenas mais tarde, com a industrialização, é que a fotografia adquiriu status de arte. A industrialização contribuiu para que a fotografia fosse utilizada para fins sociais; porém, houve uma reação contra essa utilização o que reforçou a consciência da fotografia como arte (Cf. SONTAG, 2006, p. 18). 
Sobre a aproximação do haikai com a fotografia, temos em Barthes:

O que a fotografia reproduz ao infinito só ocorre uma vez: ela repete mecanicamente o que nunca mais poderá repetir-se existencialmente [...] Ardil do vocabulário: diz-se "desenvolver uma foto", mas o que a ação química desenvolve é o indesenvolvível, uma essência (de ferida) o que não pode transformar-se, mas apenas repetir-se sob espécies de insistência (do olhar insistente). Isso aproxima a fotografia do baiku. Pois a notação de um baiku também é indesenvolvível: tudo está dado, sem provocar a vontade ou mesmo a possibilidade de uma expansão retórica (BARTHES, 1984, p. 14).

Desse modo, a poética de Paulo Leminski sugere, em momentos diversos, possuir a marca desses eventos irrepetíveis e intraduzíveis, as fotografias, como se fosse, em parte, a migração do acontecimento fortuito (o acaso) para o registro em baikais.

As fotografias podem atender ao desejo de insaciabilidade do olho e por isso nos ensinam um novo código visual: alteram e ampliam nossas idéias acerca do que vale a pena e sobre o que queremos olhar. As fotos estão dentre os mais enigmáticos objetos que constituem o ambiente que identificamos como moderno. Fotografando, apoderamo-nos do objeto fotografado, determinando nossa relação com a sociedade. Sendo as fotos, pequenos "pedaços do mundo", uma interpretação do mundo tanto quanto as pinturas e os desenhos, isto é, momento privilegiado transformado em um objeto diminuto, podemos identificá-las com os haikais, que também são um convite inesgotável ao fascínio e, portanto, à descoberta daquilo que não está totalmente explícito.

Podemos situar a poesia de Paulo Leminski, em especial, os haikais, numa condição de singularidade. No aspecto formal, seus poemas parecem revelar um movimento entre o acaso e o rigor, que se mostram numa via de mão dupla, na qual, tocados um pelo outro, saem imbuídos da presença do seu oposto. Num campo de tensão, são colocados acaso e rigor. Comunicam-se, sem cessar, relaxo e capricho, leveza e exatidão, surpresa e pensamento, traços de jogos lingüísticos que dão forma à poesia leminskiana. Logo de uma circunstância comum, passa-se para o registro poético, onde aquela é filtrada pelo olhar fotográfico do poeta, dando lugar ao inesperado.

Leminski transitou por várias tendências poéticas e dialogou com todas elas sem se deixar "aprisionar" por grupos específicos. Manteve um contato criativo com a poesia concreta e com o tropicalismo, assimilou o legado oswaldiano - e a poesia japonesa com os haikais e a linguagem visual (fotográfica), mas ousou criar a sua própria dicção e seu próprio caminho, construído de desvios às normas estabelecidas pelos cânones literários.

Assim, o "anarquiteto das desengenharias", o "samurai-malandro", o "parnasiano chic", o "guerreiro lúdico", o "bandido que sabia latim", o "cachorro lou128 A Cor das Letras - UEFS, n. 8, 2007 
co" são algumas das facetas assumidas por Paulo Leminski, que passou muito rápido pela vida lançando seu olhar de andarilho contracultural para, logo em seguida, fazer "carreira solo", à maneira das "estrelas cadentes", como no haikai a seguir:

estrela cadente eu olho

o céu partiu

para uma carreira solo (LEMINSKI apud MARINS; GÓES et al., 2002, p. 111).

\section{REFERÊNCIAS}

ASSUNÇÃO, Ademir. Leminski: dor e rigor em seus últimos poemas. Caderno de Artes e Espetáculos. Jornal da Tarde. São Paulo, 29 de setembro de 1991.

ASSUNÇÃO, Ademir. Leminski: o bandido que sabia latim. Revista Medusa, São Paulo, n. 6, 1999, p. 18.

BARTHES, Roland. A câmara clara. Trad. Júlio Castañon Guimarães. Rio de Janeiro: Nova Fronteira, 1984.

BENJAMIN, Walter. Pequena história da fotografia. In Id. Magia e técnica, arte e politica. Trad. Sérgio Paulo Rouanet. São Paulo: Brasiliense, 1993.

BENJAMIN, Walter. A obra de arte na era de sua reprodutibilidade técnica. In Id. Magia e técnica, arte e política. Trad. Sérgio Paulo Rouanet. São Paulo: Brasiliense, 1993.

BOVINCINO, Régis. Uma carta uma brasa através. São Paulo: Iluminuras, 1992.

CHAUÍ, Marilena. Janela da alma, espelho do mundo. In NOVAES, Adauto. (Org.). O olhar. São Paulo: Cia. das Letras, 1993.

FIGUEIREDO, Carmem Lúcia Negreiros de. Sedução da imagem, dilemas de cultura: a pose. Fênix - Revista de História e Estudos Culturais. São Paulo: n. 3, jul./ago./set. 2006.

FRANCHETTI, Paulo. Haikai - antologia e história. Campinas: UNICAMP, 1990.

LEMINSKI, Paulo. Agora é que são elas. São Paulo: Brasiliense, 1991.

LEMINSKI, Paulo. Anseios crípticos. Curitiba: Criar Edições, 1986

LEMINSKI, Paulo. Caprichos e relaxos. São Paulo: Brasiliense, 1983.

LEMINSKI, Paulo. Distraídos venceremos. São Paulo: Brasiliense, 1991.

LEMINSKI, Paulo. La vie em close. São Paulo: Brasiliense, 1991.

LEMINSKI, Paulo. Polonaises. Curitiba: Edição do Autor, 1980.

LEMINSKI, Paulo. Quarenta clics em Curitiba (com fotos de Jack Pires). Curitiba: Etecetera, 1976.

LEMINSKI, Paulo. Winterverno (com desenhos de João Virmond). Curitiba: Fundação Cultural de Curitiba, 1994.

MARINS, Álvaro; GÓES, Fred et al. Paulo Leminski - coleção melhores poemas. São Paulo: Global, 2002.

MARQUES, Fabrício Aço em flor: a poesia de Paulo Leminski. Belo Horizonte: Autêntica, 2001. 
MERLEAU-PONTY, Maurice. O olho e o espirito. Trad. Gerardo Dantas Barretto. Rio de Janeiro, 1969.

MOROCONI, Ítalo. Pós-modernismo e a volta ao sublime. In PEDROSA, Célia; MATOS, Cláudia; NASCIMENTO, Evando. (Org.). Poesia hoje. Rio de Janeiro: Eduff, 1998.

PERRONE-MOISÉS, Leila. Inútil poesia. São Paulo: Cia. das Letras, 2000.

PAZ, Otávio. O arco e a lira. Rio de Janeiro: Nova Fronteira, 1980.

SCHÖLLHAMMER, Karl Erik. À procura de um novo realismo. In OLINTO Heidrum; SCHÖLLMAMMER, Karl Erik. (Org.). Literatura e mídia. Rio de Janeiro: Loyola, 2002.

SCHÖLLHAMMER, Karl Erik Reflexões sobre a cultura visual e a modernidade. Cadernos de Memória. Rio de Janeiro: Museu da República, n. 1, 1995.

SONTAG, Susan. Sobre fotografia. São Paulo: Cia. das Letras, 2006.

VERÇOSA, Carlos. Paulo Leminski: a cigarra. In Oku: viajando com Bashô. Salvador: Secretaria de Cultura e Turismo do Estado da Bahia, 1996. 